\title{
Social expectations, gender and job satisfaction: Front-line employees in China's retail sector
}

Qihai Huang, Institute for Entrepreneurship and Enterprise Development, Lancaster University Management School

Jos Gamble, School of Management, Royal Holloway - University of London Human Resource Management Journal, Vol 25, no 3, 2015, pages 331-347

This study aims to enhance our understanding of gender and employment in China. Analysing data collected from over 1,800 employees at 22 foreign-invested and locally owned retail stores in eight Chinese cities, it firstly explores whether, like their counterparts in Western countries, female employees have higher levels of job satisfaction than their male colleagues. Secondly, it distinguishes the key differential predictors of female and male employees' job satisfaction levels. This article extends gender role theory on job satisfaction by showing how traditional values, the structure of work and a nation's dominant gender ideology combine to shape women and men's job satisfaction and work experiences in a transitional context.

Contact: Dr Qihai Huang, Institute for Entrepreneurship and Enterprise Development, Lancaster University Management School, Lancaster LA1 4YX, UK. Email: qihai.huang@ lancaster.ac.uk

Keywords: gender role theory; job satisfaction; multinationals; retail employment; HRM; China

\section{INTRODUCTION}

$\mathbf{T}$

he growing importance of the Chinese economy has been paralleled by increasing research on employment and human resource management in China. While this research has often touched upon gender, few studies have focused specifically on women's work and careers (Cooke and Xiao, 2014). This study aims to contribute to our understanding of gender and employment in China by drawing upon the social role theory of sex differences (Eagly, 1987). We extend this theory by showing how China's traditional values, the structure of work and a nation's dominant gender ideology combine to shape women and men's response to both the extrinsic and intrinsic dimensions of job characteristics, job satisfaction and work experiences in a transitional context.

Job satisfaction is an important aspect of the quality of work (Brown et al., 2008; Brown and Lam, 2008), and is often considered critical to organisations' success (Heskett et al., 1994; Pfeffer, 1998; Brown and Lam, 2008). An important research theme examines gender differences in job satisfaction. Frequently, this research indicates that women perceive either greater or equal levels of satisfaction in their work than men, despite being paid less or being engaged in less desirable occupations (e.g. Hodson, 1989; Clark, 1997; Sousa-Poza and Sousa-Poza, 2000a; Bender et al., 2005; Lange, 2008; Aletraris, 2010). This paradox has been explained by expectation theory. Clark (1997), for example, argues that job satisfaction is a function of expectations; if women have lower expectations about labour market outcomes, their expectations are more easily fulfilled. The assumption that women have lower expectations in the workplace can be problematic as it begs the question why this should be the case. Gender

This is an open access article under the terms of the Creative Commons Attribution License, which permits use, distribution and reproduction in any medium, provided the original work is properly cited. 
role social expectation theory (Eagly, 1987) can provide a means to better understand this issue.

Until recently, most studies on employee satisfaction have been based on data collected in Western countries, especially the United States and the United Kingdom (Nielsen and Smyth, 2008). However, determinants of job satisfaction may differ between cultures and countries (Spector, 1997). Moreover, despite increased female employment, relatively few empirical studies examine whether job satisfaction is gendered and its key determinants in developing countries (Spector et al., 2007).

Our study examines the relationship between gender and key determinants of job satisfaction among employees in China's retail sector. It addresses two main questions. Firstly, do Chinese female employees in this sector have higher levels of job satisfaction than their male counterparts like those in Western countries? Secondly, in these workplaces, what are the key predictors of job satisfaction of female and male employees respectively? This article aims to further understanding in three main respects. Firstly, it contributes to the gender and employment literature and extends gender social role theory by utilising empirical insights from a transitional context to interrogate theories drawn from Western contexts. Existing research on gender and human resource management tends to focus on the experience of well-educated and highly skilled professionals (e.g. Aaltio and Huang, 2007; Adya, 2008; Cooke et al., 2013; Cooke and Xiao, 2014), but neglects less educated and lower skilled workers such as most shopfloor employees in China's retail sector (Gamble, 2011; Huang and Gamble, 2011). Watson (2012: 238) suggests 'that workers in routine jobs both find and seek satisfaction in work less than do those in managerial, professional or highly skilled work.' Secondly, it contributes to research on front-line service work, a neglected sector despite the numerical dominance of service jobs (Kerfoot and Korczynski, 2005). Retailing alone employs over 10 per cent of the total labour force in advanced economies (Bozkurt and Grugulis, 2011). Typically, this is work in which women predominate and is often associated with jobs considered of low social status and involving poor conditions, such as low wages and limited career prospects (Bozkurt and Grugulis, 2011). In addition, work in this sector is often distinguished by interaction between service employees and customers. Thirdly, it is among the early research focusing on job satisfaction in China's retail sector. Studying this sector is important since China looks set to become the world's second largest consumer market by 2015 (American Chamber of Commerce, 2012). This makes it attractive to foreign consumer brands and retailers, which need to understand how employees' job satisfaction can be influenced in different environments (Sousa-Poza and Sousa-Poza, 2000b).

The next section reviews previous findings and arguments that explore employee satisfaction and gender. These inform the hypotheses developed and tested in this study. The article then introduces the research methods, followed by the empirical results. The final section comprises the discussion and conclusion.

\section{LITERATURE REVIEW AND HYPOTHESES DEVELOPMENT}

Job satisfaction is 'a pleasurable or positive emotional state' which is 'a function of the perceived relationship between what one wants from a job and what one perceives it is offering' (Locke, 1976: 1300). Spector (1997: 2) defines job satisfaction as 'the extent to which people like (satisfaction) or dislike (dissatisfaction) their jobs'. In essence, job satisfaction is a subjective, positive feeling or emotional state that a person perceives based on a variety of facets of the work itself and the work situation (Christen et al., 2006). Rose (2003) suggests that five main factors affect job satisfaction: the terms and conditions of the employment contract, work hours, financial rewards, the work situation (job characteristics) and the work orientation of the 
individual employee. Watson (2012) argues that satisfaction derives from factors intrinsic to or inherent in the work itself, whereas extrinsic rewards are more closely related to instrumental values. Following Rose (2003), this article focuses on key aspects that combine extrinsic dimensions (pay, job security, relationship between subordinates and superiors, working time, workload) and intrinsic dimensions (training, interaction with customers).

Available research suggests that job satisfaction correlates with a range of both positive and negative workplace outcomes. Reviewing literature in the psychology field, Locke (1976) reports that a negative correlation coefficient between job satisfaction and employee turnover was almost always obtained. Large-scale, longitudinal panel data from US sources showed job satisfaction to be negatively related to the probability of quitting (Freeman, 1978). Similarly, using data from the German Socio-Economic Panel (1984-1993), Clark et al. (1998) found that workers with lower job satisfaction had higher absenteeism and were more likely to quit. Conversely, greater employee job satisfaction is associated with lower absenteeism, reduced job turnover and better job performance (Frey and Stutzer, 2002). Meta-analyses find individual job satisfaction and job performance to be positively correlated (Petty et al., 1984; Judge et al., 2001), thus indicating its importance to organisational success.

The service literature documents a relationship between employee and customer satisfaction. Front-line retail sector sales employees are often expected to actively stimulate demand by encouraging customers to purchase a good or service. Satisfied employees are considered more likely to stimulate and meet customer demand; business success thus stems from employee satisfaction being 'reflected' in customer satisfaction (Heskett et al., 1997). In their meta-analysis, Brown and Lam (2008) find statistically significant relationships linking employee satisfaction to customer satisfaction and perceived service quality. Furthermore, better service and higher employee satisfaction frequently produce higher profits (Pfeffer, 1998). To foster employee job satisfaction, it is necessary to understand the factors that drive and underpin such positive outcomes. Gender often appears to be a potentially crucial variable in employee job satisfaction (Hodson, 1989; Clark, 1997; Bender et al., 2005; Aletraris, 2010).

Largely derived from data collected in Western countries, a central paradox in studies of gender and job satisfaction is why women's job satisfaction is often greater than men's, given that their jobs are often inferior in terms of pay, autonomy and promotion opportunity (Clark, 1997; Bender et al., 2005). Clark (1997) argues that job satisfaction is a function of expectations; women's higher job satisfaction is due to their lower expectations from work, which derives from their weaker position in the labour market, being more easily fulfilled. This explanation can be aligned with social role theory of sex differences, which emphasises the causal impact of gender roles on people's beliefs about the behaviour deemed appropriate for each sex (Eagly, 1987). In other words, men and women tend to behave in accordance with prescribed social roles both at home and in the workplace.

Such social role differences are frequently evident in three aspects: job characteristics, family responsibilities and personal expectations (Hodson, 1989; Clark, 1997; Aletraris, 2010). First, men and women tend to value characteristics of jobs and their intrinsic and extrinsic rewards differently. Second, women often focus more on their family roles rather than those as workers and thus may derive more satisfaction from the former. Third, men and women may have different personal expectations and use different comparison groups; for example, when evaluating their jobs, women are more likely to compare themselves with other working women rather than with men (Hodson, 1989). Research on gendered social roles indicates that the stress that arises from trying to simultaneously resolve conflicts between the duties involved in work roles and family roles can affect employees' job satisfaction (e.g. Scholarios and Marks, 2004; Buonocore and Russo, 2013). 
Gendered social role expectations manifest routinely in Chinese culture. The traditional norm was for families to be patriarchal and patrilineal with power invested in a male head of household (Baker, 1979). A Confucian principle captures a central feature of this sexual division of labour: 'men are primarily outside the home, women are primarily inside the home' (Leung, 2003: 360). In other words, men are expected to be the chief breadwinners, working outside the household to deliver income to the family. Women, by contrast, are assumed to take care of household work such as child rearing and day-to-day life chores (Choi and Chen, 2006). As a consequence of these norms, Chinese male and female employees can have different reactions to job characteristics, including both its extrinsic and intrinsic rewards (e.g. Clark, 1997; Aletraris, 2010).

After 1949, the Chinese state developed a 'communist gender order' which included the rhetoric of gender equality and substantively increasing women's participation in paid labour (Robinson, 1985). Between 2009 and 2013, Chinese women's labour force participation rate, measured as the proportion of the population aged 15 and older that were economically active, averaged 64 per cent, above the global average (World Bank, 2014). Gradually, the sexual division of labour became less marked and women's status improved (Zhang and Pan, 2011; Cooke and Xiao, 2014). Zhou (2000: 449) argues that 'paid employment is an indispensable part of womanhood for contemporary mainland Chinese ... The current generation of Chinese women grew up believing that working outside the home is the only way of life'.

Despite this, gender differences in employment persist (Lin and Xie, 1988; Choi and Chen, 2006; Cooke and Xiao, 2014). Indeed, evidence suggests a revival of traditional gender-based notions during the reform era (Leung, 2003; Choi and Chen, 2006). For example, Zhang and Pan (2011) argue that scaling back state efforts to create gender equality in the workplace, reinforced by marketisation, has hastened a revival of traditional gender roles and associated divisions of labour within families. Even amongst young Chinese urban professionals anticipating entry into the workforce, traditional gender roles appear pervasive; they expect women to perform more household tasks, be paid less and have less prestigious jobs (Coffey et al., 2009). Further recent research indicates that employers frequently discriminate on gender grounds (Woodhams et al., 2009). Chinese female employees are caught between contradictory expectations from their roles at home and at the workplace; they face a gap between high expectations inspired by the prevailing ideology and the reality of discrimination and inequality in the workplace as well as their typically assigned caring roles in the family. Survey data from 871 employees in Tianjin found Chinese women less satisfied with their jobs than men (Loscocco and Bose, 1998).

In the West, women's job satisfaction is reported to be higher in workplaces dominated by women (Clark, 1997; Bender et al., 2005). Since women are inclined to value job flexibility, which allows them to accommodate family issues, they tend to dominate workplaces that provide this flexibility. In interviews conducted at auditing companies in China, Cooke and Xiao (2014) found that senior managers appeared to lack sympathy regarding work-life conflicts encountered by their employees. Similarly, Gamble and Huang (2009) indicate that retail workplaces in China rarely offer any form of flexible working. Therefore it is proposed:

Hypothesis 1: Female employees in China's retail sector are significantly less satisfied with their jobs than their male counterparts.

Gender role theory can help explain why men tend to identify more with and place greater value on their work role, whereas women are more concerned with family roles (Eagly, 1987). Consequently, men emphasise the extrinsic rewards of work (such as pay and promotion) whereas women may value more highly its intrinsic returns (Clark, 1997), such as the 
opportunity for customer interaction (Mason, 1995; Gamble, 2006; Macintosh and Krush, 2014), customer appreciation (Bent and Freathy, 1997), the work itself and growth or advancement (Newman and Sheikh, 2012). In their cross-national analysis of the levels and determinants of job satisfaction, Sousa-Poza and Sousa-Poza (2000a) found that some determinants applied to all 21 countries in their study, namely, having an interesting job and good relations with management while others were country specific (such as pay and job security). Konrad et al.'s (2000) meta-analysis of gender-related studies showed men to be more concerned about earnings and responsibility, whereas women considered job security, good co-workers, good supervisors and the physical work environment more important.

In an examination of employees' organisational commitment in small and medium-sized enterprises in China, Newman and Sheikh (2012) found extrinsic rewards particularly important to employee commitment. In their research on job satisfaction and incentive structures among urban residents across 32 Chinese cities for a range of industries and ownership forms, Nielsen and Smyth (2008) report that the main determinants of job satisfaction for male workers were income and professional development opportunities, while female respondents ranked job stability, work/family balance and professional status more highly. As indicated above, Chinese men and women's roles have tended to revert to traditional expectations with men considered the main breadwinner and women as the primary caregiver and secondary income earners (Zhang and Pan, 2011). Hence:

\section{Hypothesis 2: Pay more positively affects Chinese male employees' satisfaction than it does} their female counterparts.

Research on salespeople in an international services sales environment found that training had a direct relationship with intrinsic motivation and job satisfaction (Babakus et al., 1996). Using data from the UK 2004 Workplace Employee Relations Survey, Jones et al. (2009) suggest that training is positively associated with job satisfaction, which in turn is positively associated with most measures of performance. According to Chinese social norms, the ideal man is one who 'succeeds in the world and spreads fame' (li shen yang ming) both for himself and his family through success outside the home (Yang et al., 2000). Gunkel et al. (2007) found that Chinese men attach higher importance to challenging work and training opportunities. Similarly, Nielsen and Smyth (2008) report that Chinese male workers value professional development opportunities more than their female counterparts, while female respondents ranked elements such as work/family balance and professional status more highly. Nevertheless, training can improve the ability and skills of both male and female employees; this can enable them to cope better with their jobs' demands, and thereby raise their self-confidence. Employees may also perceive training provision as a sign of the organisation's willingness to enter into a social exchange with them, and thereby result in higher levels of satisfaction (Newman and Sheikh, 2012). Therefore:

Hypothesis 3: Training is positively associated with both male and female employees' job satisfaction.

Simultaneous demands in the work and family domains can lead to role conflict (Buonocore and Russo, 2013). Job demands denote the psychological stressors involved in accomplishing the workload, including its amount and the responsibilities placed on an individual in the workplace (Karasek, 1979; Choi, 2008). Family demands refer to commitments and pressures to assume responsibilities associated with fulfilling family-related role obligations, such as spending energy, time and effort discharging family responsibilities (Yang et al., 2000). Time constraint is a key source of work-family conflict as people have limited time available to spend on work or family. Increased control over the number and timing of working hours can help 
mitigate potentially conflicting time demands. Hours of work can have a significant negative effect on overall job satisfaction (Clark, 1997). Interviews with staff in the UK retail sector revealed a pattern of increasing job satisfaction as the number of working hours decreased (Bent and Freathy, 1997).

Women are more likely to experience role conflict between career and family (Crompton, 2002), and to invest time in the family at the expense of work (Maume, 2006). Although Chinese workers tend to see extra working time as self-sacrifice made for the benefit of the family rather than a sacrifice of the family in pursuit of one's own career (Yang et al., 2000), this evaluation may apply more to men than women. Aaltio and Huang (2007) found professional women in China's IT sector had little or no personal leisure time as they spent most of their free time with their family in order to perform their domestic roles. The higher importance that Chinese male employees attach to challenging work (Gunkel et al., 2007) may indicate their willingness to cope with greater job demands and longer working time. Choi and Chen (2006) found that married female Chinese employees perceived higher family demands than their male counterparts but did not perceive any lower work demands. Therefore:

Hypothesis 4: Working time is negatively associated with female employees' job satisfaction, but not with male employees' job satisfaction.

Hypothesis 5: Workload is a negative predictor of female but not male employees' job satisfaction.

As mentioned above, in retail and other service environments, front-line workers often actively encourage customers to purchase a good or service. Customer and front-line employee interactions affect customer perceptions of the shopping and consumption experience and accordingly customer satisfaction (Brown and Lam, 2008). Concurrently, customer interaction, and customer appreciation and ability to satisfy the customer can contribute to employee satisfaction (Bent and Freathy, 1997). Gamble (2006) reports that Chinese retail store employees were often attracted by opportunities for social interaction. However, there may be a gender difference. Mason (1995) suggests that women are more satisfied with jobs in which they can interact with others in a supportive and cooperative way. In a recent article, Macintosh \& Krush (2014) find networking with customers correlated significantly with female salespersons' job satisfaction, but not with male salespersons' job satisfaction. In China, the expectation that women should 'serve' appears to extend beyond the family sphere; it tends to be accepted as normal that women predominate in much service sector work. A recent study on recruitment advertisements in China reported that female applicants were sought for 71 per cent of jobs involving selling (Woodhams et al., 2009). Therefore:

Hypothesis 6: Interaction with customers is positively associated with female but not male employees' job satisfaction.

\section{DATA AND METHODS}

Data were collected from 22 stores owned by UK and Japanese multinational retail firms and locally owned retailers in eight Chinese cities. A cross-section of over 1,800 employees completed a questionnaire, based partly upon the well-tested United Kingdom Department of Employment's Workplace Employment Relations Survey (e.g. Brown and Lam, 2008; Brown et al., 2008; Jones et al., 2009). Specific questions, some adapted for the Chinese context, were translated from the original language (English) into Chinese in discussion with Chinese colleagues to ensure their comprehensibility and applicability. Additionally, both authors are 
TABLE 1 Demographic profile of respondents (\%)

\begin{tabular}{|c|c|c|c|}
\hline \multirow{2}{*}{ Variable } & Male & Female & Total \\
\hline & 38.8 & 61.2 & 100 \\
\hline \multicolumn{4}{|l|}{ Age } \\
\hline $18-21$ & 10.3 & 10.0 & 10.1 \\
\hline $22-27$ & 56.5 & 52.7 & 54.1 \\
\hline $28-33$ & 21.9 & 28.5 & 26.0 \\
\hline $34-39$ & 6.5 & 5.6 & 5.9 \\
\hline 40 and over & 4.8 & 3.2 & 3.9 \\
\hline \multicolumn{4}{|l|}{ Marital status } \\
\hline Single & 66.8 & 52.8 & 58.3 \\
\hline Married & 33.2 & 47.2 & 41.7 \\
\hline \multicolumn{4}{|l|}{ Education } \\
\hline Junior and high school & 3.7 & 1.7 & 2.5 \\
\hline Senior high school & 56.4 & 59.6 & 58.3 \\
\hline College & 22.6 & 28.0 & 25.9 \\
\hline University & 16.5 & 10.1 & 12.6 \\
\hline Postgraduate & 0.8 & 0.6 & 0.7 \\
\hline \multicolumn{4}{|l|}{ Child } \\
\hline No child & 49.1 & 50.9 & 69.1 \\
\hline Having a child/children & 32.2 & 67.8 & 30.9 \\
\hline \multicolumn{4}{|l|}{ Ownership } \\
\hline SOE & 35.0 & 65.0 & 53.3 \\
\hline FIE & 47.2 & 52.7 & 46.7 \\
\hline \multicolumn{4}{|l|}{ Job rank } \\
\hline Ordinary employees & 36.7 & 63.4 & 69.1 \\
\hline Managerial & 39.2 & 60.8 & 30.9 \\
\hline
\end{tabular}

Chinese speakers, one being a native speaker. This version was then 'back translated' into English (Brislin, 1970). Finally, this version was compared to the original and any discrepancies resolved by mutual agreement between the two researchers (Mullen, 1995).

We supplied 2,200 questionnaires to the stores' HR departments, and they distributed them on our behalf; this ensured high (84 per cent) response rates. The questionnaire stated clearly that it was solely for research purposes and assured respondents their responses would be confidential. Completed questionnaires were returned either via a mailbox or to a designated place in the department where respondents worked. The sample for analysis in this article consists of 1,838 store employees after excluding missing values. Respondents were asked for personal background information regarding their age, gender, education level, marital status and job position.

In total, 53.3 per cent of respondents were state-owned enterprise (SOE) employees and 46.7 per cent from foreign-invested enterprises (FIEs). About two thirds (64.3 per cent) of the sample were aged below 28, with 58 per cent being single and 61 per cent female; one quarter were in managerial positions, ranging from supervisors to store managers. Most (97.5 per cent) had education equivalent to senior high school or higher (see Table 1). 


\section{Measures}

Family characteristics were measured by two variables, marital status $(1=$ married, $0=$ not married) and having a child or children under 16 years old $(1=$ yes, $0=$ no). These are similar to Hodson's (1989: 389) measurement of family responsibilities, with the latter particularly salient for women workers trying to juggle home and career responsibilities. For the working time variable, we asked respondents to give their weekly work hours. Training was measured by respondents' report of length of training received in the previous year. The interaction with customers variable distinguished job positions involving customer interaction, e.g. sales assistant, customer service and checkout (coded 1), from those that did not, including warehouse and clerical work, etc. (coded 0). The workload variable asked respondents to rate the extent 'I always have a lot of work to do'. Job security was measured by respondents' rating of the extent, 'I feel secure for my job in this company'. Both the latter were assessed with 5-point Likert scales $(1=$ strongly disagree; $5=$ strongly agree). Ownership was coded 1 if the respondent worked for a foreign-owned firm and 0 for a state-owned enterprise. Job position was coded 1 for managerial positions, otherwise 0 . The relationship question asked respondents to rate the relationship between superiors and subordinates $(1=$ very bad; $5=$ very good). These variables are in line with Rose's (2003) argument as indicated earlier. The employee satisfaction measure consisted of six items similar to Jones et al. (2009). These were assessed with 5-point Likert scales; respondents indicated the extent to which they agreed with each item ( $1=$ strongly disagree; $5=$ strongly agree). The alpha coefficient was 0.72 , higher than the suggested reliability level of 0.70 (Nunnally, 1978). Table 2 includes descriptive statistics of the above variables and the correlation matrix among them.

\section{RESULTS}

We ran t-tests to test Hypothesis 1 (see Table 3). Female employees reported significantly lower levels of job satisfaction than their male counterparts $(p=0.000)$. Therefore, Hypothesis 1 is supported. Hierarchical multiple regression analysis was used to test Hypothesis 2 to Hypothesis 6. Following previous studies (e.g. Hodson, 1989; Clark, 1997; Bender et al., 2005; Aletraris, 2010), the sample was divided and tested for men and women separately. Since the objective of this research was to examine the links between gender social role and job satisfaction, we controlled for other variables that may affect job satisfaction including store ownership, as well as age, education, job rank, and their perception of job security and the nature of the relationship between subordinates and supervisors.

Education generally raises expectations about work and is thus often negatively associated with job satisfaction (Lincoln and Kalleberg, 1990). Job security has been an important influence on job satisfaction in different countries (Brown et al., 2008; Aletraris, 2010) and also China together with the relationship between subordinates and supervisors (Gamble and Huang, 2008). Huang and Gamble (2011) suggest that job rank and ownership are significant predictors of employees' job satisfaction levels in China's retail sector. We regressed employee satisfaction on hypotheses-related variables, i.e. pay, training, working hours, workload and interaction with customers together with two variables for personal characteristics: marital status and having a child (children) below 16. In the first step, we entered the above-mentioned control variables, and then all the other variables in the regression. To check that no risk of multicollinearity was present, we conducted variance inflation factor (VIF) tests. The VIF for the variables in the model were between 1.005 and 1.338, which indicated there was no problem of multicollinearity (Hair et al., 1998). 


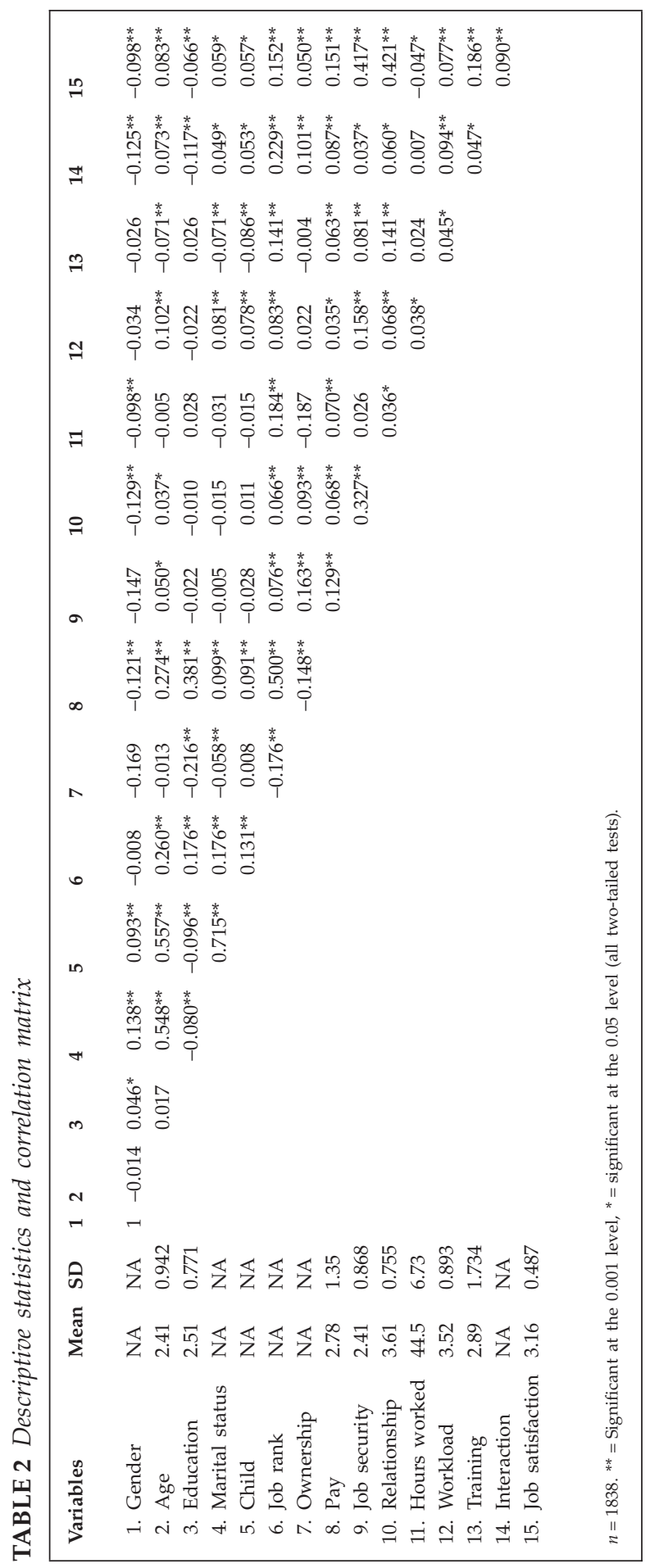


TABLE 3 t-Test results: differences between male and female in satisfaction levels

\begin{tabular}{|llllll|}
\hline Variable & Gender & Mean & Std. deviation & df & Sig. (2-tailed) \\
Satisfaction & Male & 3.2134 & 0.51116 & 1654 & $0.000^{* * *}$ \\
level & Female & 3.1275 & 0.46626 & & \\
& & & & \\
$* * * *$ Significant at the .001 level. & & & \\
\end{tabular}

Table 4 shows the results of the regression analysis. All four models were significant. Models 1 and 3 only consider the control variables. Model 2 (female) was highly significant, with an $R^{2}$ of 0.332 and an adjusted $R^{2}$ of 0.157 . Model 4 had an $R^{2}$ of 0.313 and an adjusted $R^{2}$ of 0.122 . $R^{2}$ is the percentage of the dependent variable explained by the independent variables. Models 1 and 3 only explain 18.5 and 21.1 per cent of variance, respectively. In Models 2 and 4, the independent variables explain about 31 and 33 per cent of the variance, respectively. All the control variables are significant predictors of female employee satisfaction in Model 2. All the control variables except age and ownership are associated significantly with male employees' satisfaction in Model 4.

As expected, pay is significantly associated with male employees' job satisfaction levels, but surprisingly, it does not predict female employees' job satisfaction levels. Therefore, Hypothesis 2 is only partially supported. As predicted, training is significantly and positively associated with both male and female employees' job satisfaction. Therefore, Hypothesis 3 is supported. Working hours are significantly and negatively associated with female employees' but not male employees' job satisfaction. Accordingly, Hypothesis 4 is supported. Workload is not associated with either female or male employees' satisfaction ( $p=0.969$ and 0.684 , respectively). Therefore, Hypothesis 5 is only partially supported. Interaction with customers, a key characteristic of retail work, predicts positively and significantly female employees' satisfaction levels. It appears to have a negative association with male employees' satisfaction levels, although the relationship is not statistically significant. Therefore, Hypothesis 6 is supported. Neither marital status nor having children is associated with either male or female employees' job satisfaction levels. These two personal characteristics measuring family responsibilities appear not to predict job satisfaction levels for either male or female employees in China.

\section{DISCUSSION}

This study aims to shed light on our understanding of gender and employment in China. More specifically, it assesses the extent to which gender social role expectations interact with extrinsic and intrinsic elements of the job and influence employee experience and satisfaction levels in China. Firstly, our data show that female employees in the retail sector reported significantly lower levels of job satisfaction. This contrasts with much other available research, largely based on data from the UK and US, which tends to show the so-called paradox of the contented female employee. Additionally, existing research suggests that female job satisfaction tends to increase as the female share of the workplace increases (Clark, 1997; Bender et al., 2005). Although China's retail sector is dominated by female employees, with 61 per cent of our employee sample being female, our data do not lend support to this view either. Our finding accords with Sousa-Poza and Sousa-Poza's (2000a) cross-national study. It also echoes Lange's (2008) research, which reports substantial differences between male and female employees in 


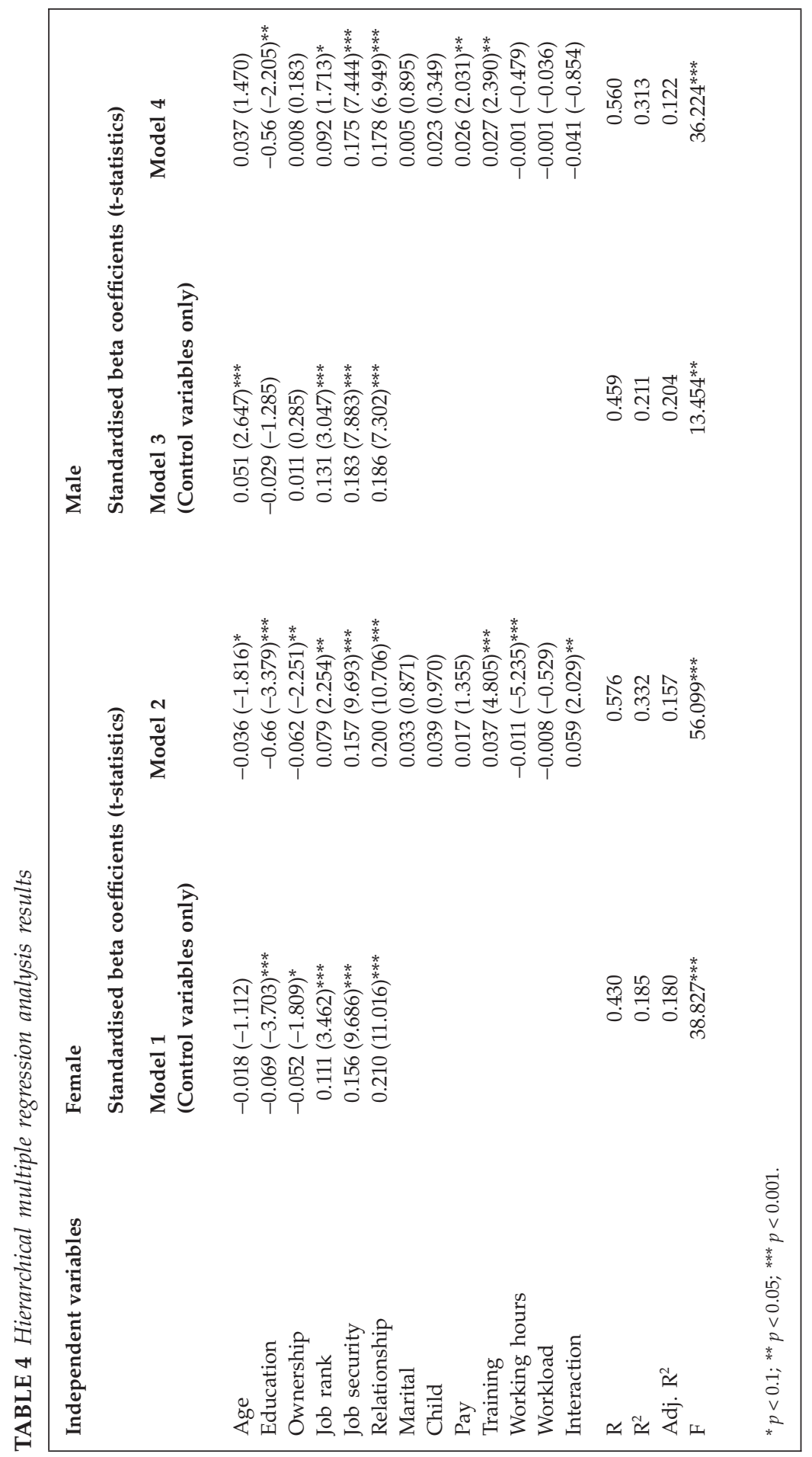


his sample from Central and Eastern European countries. He argues that some of these differences reflect the persistent influence of a communist gender order, while others suggest the importance of post-communist experiences.

Secondly, our further analysis revealed that intrinsic and extrinsic job characteristics impact differentially on female and male employees' job satisfaction levels. This illuminates the way in which traditional values, the structure of work and a nation's dominant gender ideology combine to shape women and men's work experiences. Two of the determinants of job satisfaction included in our analysis appear to have a similar impact on both female and male employees, namely, training and workload, while the others differ substantially. Training appears to be a significant predictor of both male and female employees' job satisfaction levels. It might be that Chinese women have been inspired by the communist gender order and consider themselves equal to men (Zhou, 2000). Therefore, they value training opportunities and career development. A surprising finding is that workload does not predict job satisfaction for either male or female employees. This might indicate that both female and male employees in China adapt to cope with varying levels of workload; as a senior manager commented about demanding work in auditing, 'women are used like men, and men are used like animals' (Cooke and Xiao, 2014). Personal characteristics which indicated family responsibilities, i.e. marriage and having young children, were not associated with either male or female employees' job satisfaction levels. There is a need to look at the broader support beyond the individual employees that helps alleviate work-family pressures. For example, parents in China often help married children with household chores and child-care (Yang et al., 2000).

The impact of three determinants, income, interaction with customers and working hours, on job satisfaction appear to be gendered. Income is associated significantly with male but not female employees' job satisfaction levels. This accords with findings from OECD countries (e.g. Clark, 1997; Konrad et al., 2000) as well as those found earlier in China (Nielsen and Smyth, 2008). While female employees' job satisfaction declines significantly with hours worked, this variable is not associated with male employees' job satisfaction levels. It may be less problematic for male employees to work long hours; it might be regarded as self-sacrifice for career development and success outside the home, which in turn can contribute to the family (Yang et al., 2000). However, long hours can be problematic for female employees, as women still bear greater responsibility for managing the family household (Leung, 2003). Thus, it is unsurprising to find that women appear to value time away from demanding work schedules more highly than do their male counterparts.

Similarly, the finding that interaction with customers significantly increases female but not male employees' job satisfaction could be explained by Chinese cultural norms. Women in China have long played a secondary and subordinate role in the public domain (Lin and Xie, 1988). The expectation that women should 'serve' appears to extend beyond the family sphere. Chinese people tend to accept it as normal for women to work in service sector occupations. Conversely, it appears more difficult for male employees to feel comfortable serving customers. Some male employees interviewed during our fieldwork satirised the way their work role required them to play the part of an inferior to customers, describing it as 'a big master to serve others' (da laoye men ci hou bie ren). Consequently, while interaction with customers can, in general, be a source of satisfaction to retail sector employees (Bent and Freathy, 1997; Gamble, 2006), Chinese male and female employees appear to value this interaction differently. Our finding is consistent with Macintosh \& Krush's (2014) finding that networking with customers related positively to saleswomen but not salesmen's job satisfaction. As Watson (2012) points out, there are occupational similarities in work meanings across different countries; the moderating impact of deeply embedded and gendered social expectations needs to be considered. 
As in other transitional economies, economic reforms that have shifted China towards a market economy appear to have increased gender disparities in the labour market and simulated a revival of more traditional gendered divisions of labour within families (Zhang and Pan, 2011). Our findings might reflect an impact of the transitional context on gender role expectations of Chinese employees. The gap between expectations of gender equality and female participation in the workforce inspired by state ideology and the reality of inequality in the workplace may contribute to the significantly different levels of job satisfaction between male and female employees and also to the differential impact of determinants of job satisfaction. The Chinese state's declared intention is to create more equitable gender relations at work and to weaken gendered divisions of labour in families. However, traditional beliefs, together with the failure to fully implement the espoused rhetoric, continue to shape and constrain both the social status of Chinese women and their role in the workplace.

Inspired by the communist gender order, Chinese women may believe themselves equal to men and to 'hold up half of the sky' (Zhou, 2000). Meanwhile, role expectations embedded in traditional value systems, as reproduced and handed on within families, can be contradictory to the espoused gender order. Such contradictions are evident in our findings. For example, pay does not significantly predict female employees' satisfaction, probably because the role of 'breadwinner' continues to be perceived widely as a male responsibility while women are expected to contribute more to looking after the family, with their wages considered as a supplement to family incomes. As Zhang and Pan (2011) point out, women's roles as wives, mothers and caregivers in the family cause work-family conflict and constrain their job choices. If women want to select family-friendly waged employment, they usually face jobs which are devalued and lower-paid, and suffer a penalty in wages and career advancement.

We should, though, avoid over attributing explanations to gender role expectations, since we found that having children, potentially an important indicator of family responsibilities, did not appear to affect satisfaction levels. Other factors may be important. For example, our questionnaire did not enquire whether the extended family help look after respondents' children; this could substantially alleviate pressure from family obligations. Loscocco and Bose (1998) argue that gender differences in satisfaction reflect women's economic disadvantage; men's satisfaction, however, is more closely tied to individual features, such as education and age. It may be that elements related to women's economic or social disadvantage contribute more to lower levels of female employees' job satisfaction; as we indicated earlier, the independent variables we included in our analysis explain only about 31 and 33 per cent of the variance, respectively in male and female job satisfaction.

\section{Limitations}

Limitations of our research include its cross-sectional design; caution is necessary when inferring causality between the variables in such studies. In addition, subtle dimensions can be hard to capture using a quantitative survey-based approach. Thus, for instance, hours of work tell us little about the extent and nature of work intensification, which may differ markedly. As suggested in the previous paragraph, further research is also needed to more fully understand the nature of work-family conflicts and their impact on job satisfaction. Future research can also develop specific questions to measure respondents' perceptions of their gender role expectations. Our research also focused on a single industry; future studies could involve comparative research. 


\section{CONCLUSIONS AND IMPLICATIONS}

Using survey data collected from employees working in foreign multinational and domestic retailers in China, this article assesses the extent to which gender role expectations can influence job satisfaction. Firstly, we showed that Chinese female employees in the retail sector have significantly lower levels of job satisfaction than their male counterparts, contrary to findings in some Western countries (e.g. Clark, 1997). This mirrors Loscocco and Bose's (1998) finding from the early reform era that overall Chinese women were less satisfied with their jobs than men. Secondly, some key determinants of job satisfaction, notably training and workload, appeared to have an equal impact on both female and male employees' satisfaction. The differences lie in the other key variables, pay, interaction with customers and hours of work.

Pay is a significant predictor of male employees' job satisfaction, but does not appear to be a good predictor of females' job satisfaction. Female job satisfaction levels decline significantly with hours worked, but are not associated with male employees' job satisfaction level. The job characteristic of interaction with customers is significantly associated with female employees' job satisfaction, but not male employees'. Our analysis points either to women's expectations rising and being thwarted by the discrimination they face in the workplace and/or to their objective conditions in the workplace having deteriorated during the reform period. Meanwhile, traditional gender role norms appear likely to affect their job satisfaction; these include, for example, the expectation that women will play the main role in performing domestic duties such as care of children and the elderly (Choi and Chen, 2006; Cooke and Xiao, 2014), despite also facing heavy demands in the workplace. Our results suggest that gender role expectations embedded in Chinese culture and the legacy of the communist gender equality ideology intertwine and combine to influence employees' work experience, including job satisfaction, in a complex and sometimes contradictory manner in a time of economic and social transition.

Our findings have implications for employment and human resource management policy. Since female employees are more likely to be caught by work-family conflict, family-friendly policies or the use of part-time work, both rare in the Chinese context, can provide relief for employees with young children. Such provision can have positive benefits not only for employees, but also for their organisations. Scholarios and Marks (2004) suggest that work-life balance can affect employees' trust in their organisation which in turn can influence their job satisfaction and organisational commitment. Further, Bender et al. (2005) argue that women value job flexibility, which allows them to accommodate family issues, and tend to be attracted to workplaces that provide this flexibility. A worthwhile future topic would be to explore employee responses to and the management implications of flexible work arrangements in the Chinese context. Control over the timing and duration of work permits greater flexibility in balancing work and non-work roles; this might be particularly attractive for China's female employees.

Both male and female employees appear to value equally training opportunities and thus probably career development. The rhetoric of equality in the communist gender order and the attendant expectation that women should work full-time appears to have inspired in Chinese women the ambition to advance their personal and career development. Managers need to consider how they can facilitate this desire. As Cooke and Xiao (2014) suggest, female professionals, for instance, face more barriers in their working lives. Human resource policies need to consider the benefits and job attributes that are important to employees, taking into consideration the differential social norms and expectations that apply to men and women. The 
positive message is that policies designed to meet employees' needs seem likely not only to improve employee satisfaction but also help to enhance firms' attraction as employers and their performance in the marketplace.

\section{REFERENCES}

Aaltio, I. and Huang, J. (2007). 'Women managers' careers in information technology in China: high flyers with emotional costs?'. Journal of Organizational Change Management, 20: 2, 227-244.

Adya, M. (2008). 'Women at work: differences in IT career experiences and perceptions between South Asian and American women'. Human Resource Management, 47: 3, 601-635.

Aletraris, L. (2010). 'How satisfied are they and why? A study of job satisfaction, job rewards, gender and temporary agency workers in Australia'. Human Relations, 63: 8, 1129-1155.

American Chamber of Commerce (2012). China Consumer Market Strategies. American Chamber of Commerce: Shanghai. http://www.amcham-shanghai.org/ftpuploadfiles/Publications/China ConsumerMarketStrategies/China_Consumer_Market_Strategies_2012_Report.pdf, accessed 14 January 2014.

Babakus, E., Cravens, D.W., Johnston, M. and Moncrief, W.C. (1996). 'Examining the role of organizational variables in the salesperson job satisfaction model'. Journal of Personal Selling $\mathcal{E}$ Sales Management, 16: 3, 33-46.

Baker, H.D. (1979). Chinese Family and Kinship, New York: Columbia University Press.

Bender, K.A., Donohue, S.M. and Heywood, J.S. (2005). 'Job satisfaction and gender segregation'. Oxford Economic Papers, 57: 3, 479-496.

Bent, R. and Freathy, J.P. (1997). 'Motivating the employee in the independent retail sector'. Journal of Retailing and Consumer Services, 4: 3, 201-208.

Bozkurt, Ö. and Grugulis, I. (2011). 'Why retail work demands a closer look', in I. Grugulis and Ö. Bozkurt (eds), Retail Work, Basingstoke: Palgrave Macmillan.

Brislin, R. (1970). 'Back-translation for cross-cultural research'. Journal of Cross-Cultural Psychology, 1: 3, 185-216.

Brown, A., Forde, C. and Spencer, D. (2008). 'Changes in HRM and job satisfaction, 1998-2004: evidence from the Workplace Employment Relations Survey'. Human Resource Management Journal, 18: 3, 237-256.

Brown, S.P. and Lam, S.K. (2008). 'A meta-analysis of relationships linking employee satisfaction to customer responses'. Journal of Retailing, 84: 3, 243-255.

Buonocore, F. and Russo, M. (2013). 'Reducing the effects of work-family conflict on job satisfaction: the kind of commitment matters'. Human Resource Management Journal, 23: 1, 91-108.

Choi, J. (2008). 'Work and family demands and life stress among Chinese employees: the mediating effect of work-family conflict'. The International Journal of Human Resource Management, 19: 5, 878-895.

Choi, J. and Chen, C.C. (2006). 'Gender differences in perceived work demands, family demands, and life stress among married Chinese employees'. Management and Organization Review, 2: 2, 209-229.

Christen, M., Lyer, G. and Soberman, D. (2006). 'Job satisfaction, job performance, and effort: a reexamination using agency theory'. Journal of Marketing, 70: 1, 137-150.

Clark, A. (1997). 'Why are women so happy at work?'. Labour Economics, 4, 341-372.

Clark, A., Georgellis, Y. and Sanfey, P. (1998). 'Job satisfaction, wage changes and quits: evidence from Germany'. Research in Labor Economics, 17, 95-122.

Coffey, B.S., Anderson, S., Zhao, S. and Liu, Y. (2009). 'Perspectives on work-family issues in China: the voices of young urban professionals'. Community, Work \& Family, 12: 2, 197-212.

Cooke, F.L. and Xiao, Y.C. (2014). 'Gender roles and organizational HR practices: the case of women's careers in accountancy and consultancy firms in China'. Human Resource Management, 53: 1, 23-44.

Cooke, F.L., Lin, Z.H. and Jiang, Y.M. (2013). 'Who are "managing" the lawyers in China? Control and commitment in an evolving institutional and cultural context and gendered implications'. The International Journal of Human Resource Management, 24: 18, 3418-3437. 
Crompton, R. (2002). 'Employment, flexible working, and the family'. British Journal of Sociology, 53: $4,537-558$.

Eagly, A.H. (1987). Sex Differences in Social Behavior: A Social-role Interpretation, Hillsdale, NJ: Lawrence Eribaum.

Freeman, R. (1978). 'Job satisfaction as an economic variable'. American Economic Review, 68: 2, $135-141$.

Frey, B. and Stutzer, A. (2002). 'What can economists learn from happiness research?'. Journal of Economic Literature, XL: 2, 402-435.

Gamble, J. (2006). 'Introducing Western-style HRM practices to China: shopfloor perceptions in a British multinational'. Journal of World Business, 41: 4, 328-343.

Gamble, J. (2011). Multinational Retailers and Consumers in China: Transferring Organizational Practices from the United Kingdom and Japan, London: Palgrave.

Gamble, J. and Huang, Q.H. (2008). 'Organizational commitment of Chinese employees in foreign-invested firms'. The International Journal of Human Resource Management, 19: 5, 896915.

Gamble, J. and Huang, Q.H. (2009). 'One store, two employment systems: core, periphery and flexibility in China's retail sector'. British Journal of Industrial Relations, 47: 1, 1-26.

Gunkel, M., Lusk, E.J., Wolff, B. and Li, F. (2007). 'Gender-specific effects at work: an empirical study of four countries'. Gender, Work \& Organization, 14: 1, 56-79.

Hair, J., Andersen, R., Tatham, R. and Black, W. (1998). Multivariate Data Analysis, Upper Saddle River, NJ: Prentice Hall.

Heskett, J.L., Jones, T.O., Loveman, G.W., Sasser, W.E. Jr. and Schlesinger, L.A. (1994). ‘Putting the service-profit chain to work'. Harvard Business Review, 72: 2, 164-174.

Heskett, J.L., Sasser, W.E. Jr. and Schlesinger, L.A. (1997). The Service Profit Chain: How Leading Companies Link Profit and Growth to Loyalty, Satisfaction and Value, New York: Free Press.

Hodson, R. (1989). 'Gender differences in job satisfaction: why aren't women more dissatisfied?'. Sociological Quarterly, 30: 3, 385-399.

Huang, Q.H. and Gamble, J. (2011). 'Informal institutional constraints and their impact on HRM and employee satisfaction: evidence from China's retail sector'. The International Journal of Human Resource Management, 22: 15, 3168-3186.

Jones, M., Jones, J., Latreille, P. and Sloane, P. (2009). 'Training, job satisfaction and workplace performance in Britain: evidence from WERS 2004'. Labour (Committee on Canadian Labour History), 23: s1, 139-175.

Judge, T.A., Thoresen, C.J., Bono, J.E. and Patton, G.K. (2001). ‘The job satisfaction-job performance relationship: a qualitative and quantitative review'. Psychological Bulletin, 127: 3, 376-407.

Karasek, R.A. (1979). 'Job demands, job decision latitude, and mental strain: implications for job redesign'. Administrative Science Quarterly, 24: 2, 285-310.

Kerfoot, D. and Korczynski, M. (2005). 'Gender and service: new directions for the study of "front-line" service work'. Gender, Work \& Organization, 12: 5, 387-399.

Konrad, A.M., Corrigall, E., Lieb, P. and Ritchie, J.E. Jr. (2000). 'Sex differences in job attribute preferences among managers and business students'. Group \& Organization Management, 25: 2, $108-130$.

Lange, T. (2008). 'Communist legacies, gender and the impact on job satisfaction in Central and Eastern Europe'. European Journal of Industrial Relations, 14: 3, 327-346.

Leung, A.S.M. (2003). 'Feminism in transition: Chinese culture, ideology and the development of the women's movement in China'. Asia Pacific Journal of Management, 3: 9, 359-374.

Lin, N. and Xie, W. (1988). 'Occupational prestige in urban China'. American Journal of Sociology, 93: 4, 793-832.

Lincoln, J. and Kalleberg, A. (1990). Culture, Control, and Commitment: A Study of Work Organization and Work Attitude in the United States and Japan, New York: Cambridge University Press.

Locke, E.A. (1976). 'The nature and causes of job satisfaction', in M.D. Dunnette (ed.), Handbook of Industrial and Organizational Behavior, Chicago, IL: Rand McNally. 
Loscocco, K.A. and Bose, C.E. (1998). 'Gender and job satisfaction in urban China: the early post-Mao period'. Social Science Quarterly, 79: 1, 91-109.

Macintosh, G. and Krush, M. (2014). 'Examining the link between salesperson networking behaviors, job satisfaction, and organizational commitment: does gender matter?'. Journal of Business Research, 67: 12, 2628-2635.

Mason, S.E. (1995). 'Gender differences in job satisfaction'. The Journal of Social Psychology, 135: 2, 143-151.

Maume, D. (2006). 'Gender differences in restricting work efforts because of family responsibilities'. Journal of Marriage and Family, 68: 4, 859-869.

Mullen, M.R. (1995). 'Diagnosing measurement equivalence in cross-national research'. Journal of International Business Studies, 26: 3, 573-596.

Newman, A. and Sheikh, A.Z. (2012). 'Organizational commitment in Chinese small and medium-sized enterprises: the role of extrinsic, intrinsic and social rewards'. The International Journal of Human Resource Management, 23: 2, 349-367.

Nielsen, I. and Smyth, R. (2008). 'Job satisfaction and response to incentives among China's urban workforce'. Journal of Socio-Economics, 37: 5, 1921-1936.

Nunnally, J.C. (1978). Psychometric Theory, 2nd edn, New York: McGraw-Hill.

Petty, M., McGee, G.W. and Cavender, J.W. (1984). 'A meta-analysis of the relationships between individual job satisfaction and individual performance'. The Academy of Management Review, 9, 712-721.

Pfeffer, J. (1998). The Human Equation: Building Profits by Putting People First, Boston, MA: Harvard Business School Press.

Robinson, J.C. (1985). 'Of women and washing machines: employment, housework and the reproduction of motherhood in socialist China'. China Quarterly, 10, 32-57.

Rose, M. (2003). 'Good deal, bad deal? Job satisfaction in occupations'. Work, Employment and Society, 17: 3, 503-530.

Scholarios, D.M. and Marks, A. (2004). 'Work-life balance and the software worker'. Human Resource Management Journal, 14: 2, 54-74.

Sousa-Poza, A. and Sousa-Poza, A. (2000a). 'Taking another look at the gender/job satisfaction paradox'. Kyklos, 53: 2, 135-152.

Sousa-Poza, A. and Sousa-Poza, A. (2000b). 'Well-being at work: a cross-national analysis of the levels and determinants of job satisfaction'. Journal of Socio-Economics, 29: 6, 517-538.

Spector, P.E. (1997). Job Satisfaction: Application, Assessment, Causes and Consequences, Thousand Oaks, CA: Sage.

Spector, P.E., Allen, T.D., Poelmans, S.A.Y. et al. (2007). 'Cross-national differences in relationships of work demands, job satisfaction, and turnover intentions with work-family conflict'. Personnel Psychology, 60: 4, 805-835.

Watson, T.J. (2012). Sociology, Work and Organisation, London: Routledge.

Woodhams, C., Lupton, B. and Xian, H. (2009). 'The persistence of gender discrimination in China - evidence from recruitment advertisements'. The International Journal of Human Resource Management, 20: 10, 2084-2109.

World Bank (2014). Labor Force Participation Rate. http://www.data.worldbank.org/indicator/ SL.TLF.CACT.FE.ZS, accessed 18 August 2014.

Yang, N., Chen, C.C., Choi, J. and Zou, Y. (2000). 'Sources of work-family conflict: a Sino-U.S. comparison of the effects of work and family demands'. Academy of Management Journal, 43: 1, 113-123.

Zhang, Q.F. and Pan, Z. (2011). 'Women's entry into self-employment in urban China: the role of family in creating gendered mobility patterns'. World Development, 40: 6, 1201-1212.

Zhou, Y. (2000). "The fall of "the other half of the sky"? Chinese immigrant women in the New York area'. Women's Studies International Forum, 23: 4, 445-459. 